\title{
Defining the Temperature Change of the Brake Disc
}

\author{
M. Menyhártné Baracskai \\ Széchenyi István University \\ Department of Mechatronics and Machine Design \\ H-9026 Győr, Hungary, Egyetem tér 1. \\ e-mail: baramel@sze.hu
}

\begin{abstract}
In the article the thermal analysis of the brake disc and separator disc of a high performance power machine will be presented. As example an agricultural vehicle with weight of $30000 \mathrm{~kg}$ and maximum travel speed of $40 \mathrm{~km} / \mathrm{h}$ will be taken. At stopping the vehicle, the braking system located in the wheel body becomes activated. The traversing of the piston forces the brake discs to friction. Therefore significant amount of heat is generated, which needs to be derived from the system. The article presents the construction of the disc brake system. Providing boundary condition, the radial temperature change of the cooled part of the brake disc will be defined.
\end{abstract}

Keywords: agricultural vehicle, disc brake, brake oil, braking, temperature

\section{Description of braking from the thermal aspect}

As shown on Figure 1 the disc brake equipment is located in the wheel body. During motion of the vehicle, while there is no braking, the brake equipment is in open position. The individual discs are not in contact with each other. The brake house is filled with oil up to $19 \mathrm{~mm}$ height over the shaft centre. Heat exchanging processes are carried out between the elements of the equipment in contact with oil. During braking, the hydraulic presses the rotating discs, therefore they are closing. A featuring characteristic of the brake discs is that they are equipped with grooved friction surface. During braking, the cooling oil leaves the system through the grooves and heat exchanging processes are carried out between the discs in contact with each other. When braking is completed, the discs open up again and the oil re- 
flows into the brake discs between. It warms up there and cause the centrifugal force as result of the rotating move, the oil is splashed against the wall of the brake house. Some of the generated amount of heat is passed on to the environment. The part of the heat remaining in the system is derived by a water cooling heat exchanger. The oil cooler connected to the subject unit is equipped with a pump providing 16 litres/min flow rate, through which the oil is delivered.

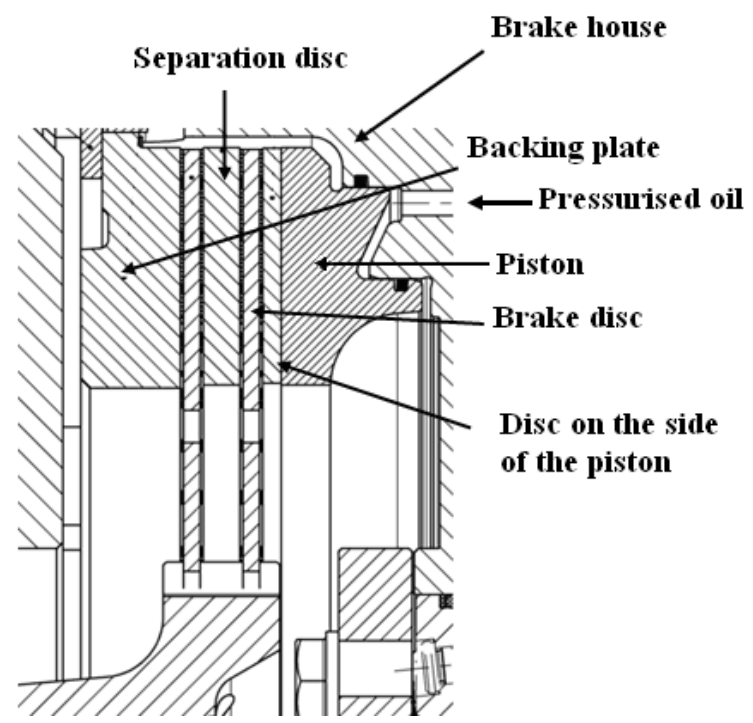

Figure 1. Major elements inside the wheel body

\section{Description of the temperature values necessary for the calculations}

By using temperature sensor located in the separator disc the generated temperature was measured. During the measurement braking was examined at a slowing rate of $2 \mathrm{~m} / \mathrm{s}^{2}$ from $40 \mathrm{~km} / \mathrm{h}$ until completely stopping. As the result of the braking, the highest temperature of the brake disc $234^{\circ} \mathrm{C}$ is obtained. Prior to writing the differential equation, computer aided simulation was carried out on the brake unit for the purpose of learning the average temperature values generated on the biggest radius of each disc. For the simulation Nastran software was used. As result of the simulation the temperature on the external radius of the separator disc is $186.7^{\circ} \mathrm{C}$, and in case of the brake disc is $172.2^{\circ} \mathrm{C}$. 

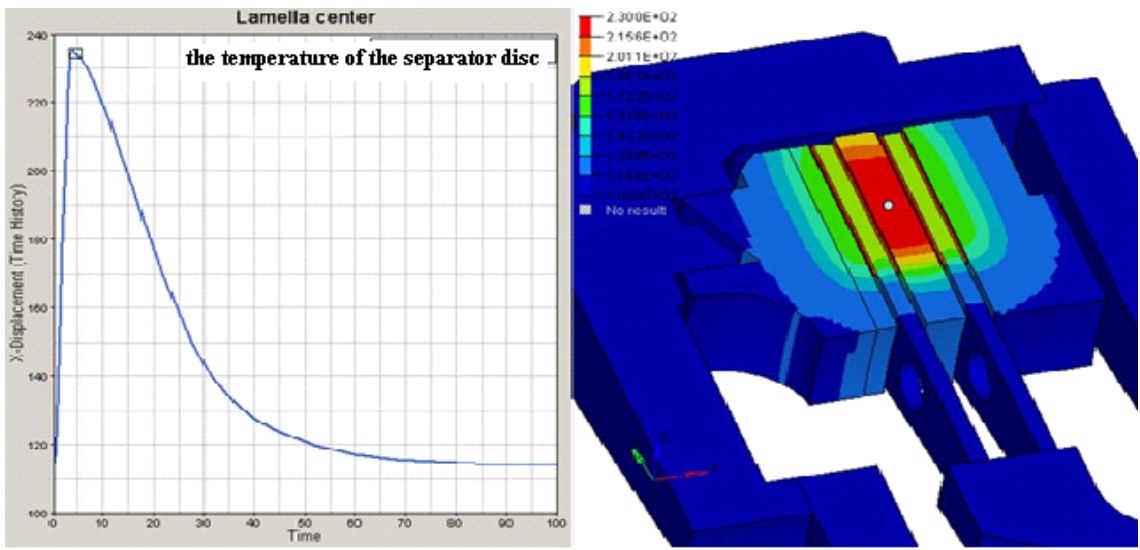

Figure 2. Results of the computer aided simulation

As on the diagram can be seen, during the braking the temperature in the place of the measuring device placed inside the separator disc increases to $234{ }^{\circ} \mathrm{C}$, then, as a result of the heat derivation by the cooling oil, drops very quickly to $115^{\circ} \mathrm{C}$.

As shown on the Figure the separator disc receives the highest heat load. The asbestos friction layer pressed on the two sides of the brake discs have rather poor heat conduction capacity almost insulating the discs. That is why the temperature of the brake discs is lower, while the friction layer is high, reaches $230{ }^{\circ} \mathrm{C}$.

\section{Writing the heat conduction-exchange differential equation for the cooled part of the brake disc in order to define the temperature rate distribution of the disc.}

During the braking process, the energy of motion of the vehicle turns to be work of friction, whereas heat is generated. As the result of braking, the upper part of the brake disc and of the separator disc are subject to bearing quite high heat load. The lower part of the discs is being cooled. The heat conduction-exchange differential equation for the cooled part of the brake disc can be formed.

The temperature change of the disc needs to be defined in order to see the life cycle in use and shelf life of the brake oil. The life cycle of the brake oil was analysed with Differential Scanning Calorimeter (DSC) in inert (nitrogen) atmosphere. The results of the oil analysis gained through the help of the DSC device are to be presented in Article [12]. 
The life cycle of the oil is definitely featured by the boundary layer of the oil adhering on the disc. The temperature of the boundary layer almost equals with that of the disc. Therefore the temperature change of the disc needs to be examined. [10]

The temperature change of the disc in balance of the radius has to be defined by a heat conduction-exchange differential equation written for one element of the rotating disc. It is presented in the following.

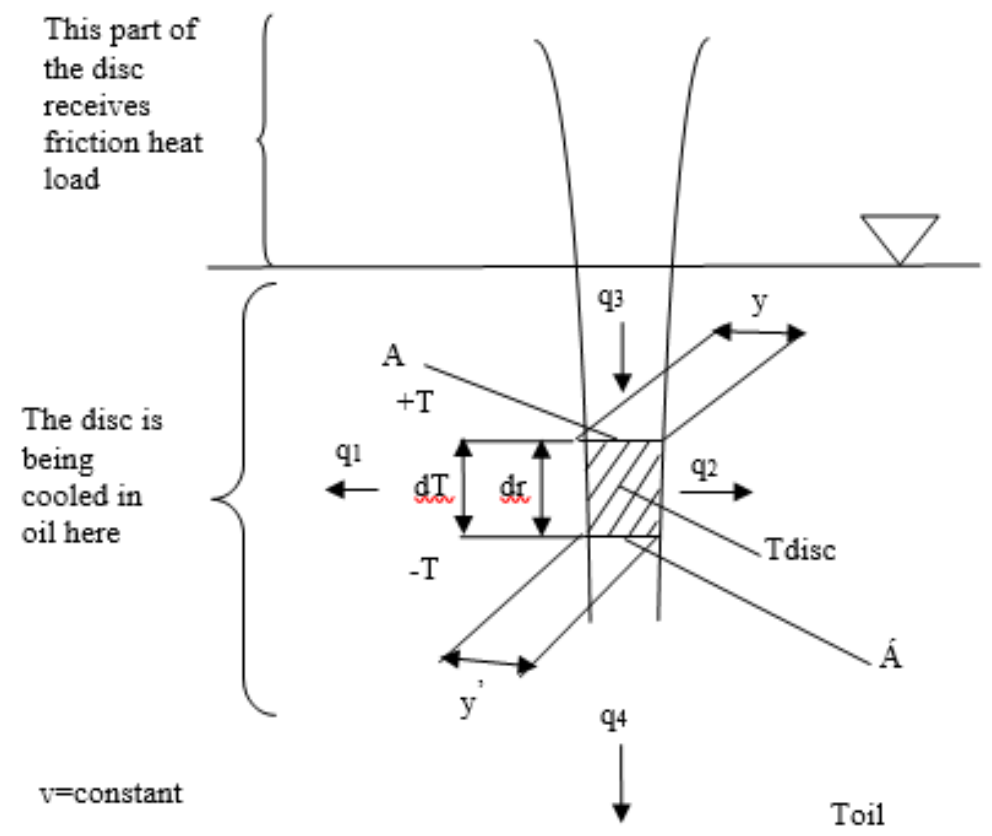

Figure 3. Dimensions of one element of the disc and the heat loads acting upon it Whereas:

$q 1$ and $q 2$ are the heat mounts leaving through the wall of the element by heat transfer (because of the oil cooling)

$q 3$ and $q 4$ are the heat mounts leaving through the horizontal surface of the disc by heat conduction.

$T$ is the temperature of the examined element

Toil is the temperature of the cooling oil

$A$ is the surface of the disc element provided on the heat conduction side radius $(r+d r)$ of the disc

$A$ is the surface provided on the r radius 
As the result of braking, the temperature of the separator disc is increasing to the highest value of all the parts of the brake system. Therefore is reasonable to write the heat conduction-exchange differential equation for the separate disc. The temperature on the external radius of the separator disc, where cooling begins is $186.7^{\circ} \mathrm{C}$. The temperature of the cooling oil can be considered as constant to be 80 ${ }^{\circ} \mathrm{C}$ since a high flow rate pump immediately forwards the cooling heated oil to the water-cooled oil cooler.

As boundary condition, $186.7^{\circ} \mathrm{C}$ temperature is taken in one point of the diameter of the separator disc. This is because the subject is to examine the state belonging to the maximum heat load.

The temperature in the subject case does not change in time; however, it depends on the place. Only an amount of heat can enter the thermodynamic system, which is enough for maintaining the $186.7^{\circ} \mathrm{C}$ as measured on the edge of the disc. Since the temperature of the cooling oil is lower than the temperature of the edge of the disc, therefore it is expected during the examination that the temperature of the brake disc will decrease towards the centre.

At writing the temperature, the entering and leaving amounts of heat need to be of 0 values. Further, the entering amount of heat will be + , while the leaving heat amount will be -.

$$
+q_{3}-q_{4}-\left(q_{1}+q_{2}\right)=0
$$

Since the thickness of the disc element is changing, the calculation is two differentially altering surfaces while writing the equation.

$$
\begin{aligned}
& A^{\prime}=2 \cdot \pi \cdot r \cdot y^{\prime} \\
& A=2 \cdot \pi \cdot r \cdot y
\end{aligned}
$$

where:

$A$ is the surface of the examined element provided on the heat conduction side $(r+d r)$ radius, $A$ is the surface provided on the radius.

$$
\begin{aligned}
& q_{3}=\lambda \cdot 2 \cdot \pi \cdot r \cdot y \frac{d T}{d r} \\
& q_{4}=\lambda \cdot 2 \cdot \pi \cdot r \cdot y^{\prime} \frac{d T}{d r}
\end{aligned}
$$


If $y=$ constant, and $d r$ is of elemental size.

$$
q_{3}-q_{4}=\lambda \cdot A \frac{d T}{d r}-\lambda \cdot A^{\prime} \frac{d T^{\prime}}{d r}=\lambda \frac{d}{d r}\left(A \frac{d T}{d r}\right) d r
$$

The $A^{\prime}<A, \quad A \frac{d T}{d r}$ and the $A^{\prime} \frac{d T^{\prime}}{d r}$ are differentially altering from each other; therefore the equation sourcing from the heat conduction is:

$$
\lambda d\left(A \frac{d T}{d r}\right)=\lambda \frac{d}{d r}\left(A \frac{d T}{d r}\right) d r=q_{3}-q_{4}
$$

The heat amount leaving through the side walls of the element sources from the heat transfer between the disc and the oil. Since q1 and q2 are equal, a duplicator enters the equation.

$$
q_{1}+q_{2}=4 \cdot \alpha_{o l} \cdot \pi \cdot r d r\left(T_{\text {disc }}-T_{\text {oil }}\right)
$$

where:

the $\alpha_{o l}$ is the oil heat transfer factor is constant along the radius of the disc.

The complete differential equation is given from the evaluation of the above tags with the right algebraical sign back to the heat balance:

$$
\lambda \frac{d}{d r} \cdot\left(A_{(r)} \frac{d T_{(r)}}{d r}\right) d r-4 \alpha_{o l} \cdot \pi \cdot r d r\left(T_{\text {disc }}-T_{o i l}\right)=0
$$

With the exception of the heat conduction factor, all factors depend on the radius and the heat transfer factor of the oil is constant.

The direct solution of the (9) differential equation is rather complicated and long lasting. Even with providing certain conditions (disc and temperature rates etc.), it is only approximately possible. Therefore, the transformation of the equation to be a differential equation is taken by the choice. Although in principle it is less accurate, in case an appropriately low value $\Delta r$-s are selected, the final result would be eventually more accurate for it is not bond to various restricting conditions.

The second term in the equation can also be calculated directly as a differential equation, since $(\mathrm{dr} \sim \Delta \mathrm{r})$, Tdisc(r) changes by $\Delta \mathrm{T}$.

Transferring the first term to be a differential equation is as follows. 
The first term's $\left(A_{(r)} \frac{d T_{(r)}}{d r}\right)$-t as product is derived.

$$
\lambda\left\{\left[\frac{d A_{(r)}}{d r} \cdot \frac{d T_{(r)}}{d r}+A_{(r)} \frac{d^{2} T_{(r)}}{d r^{2}}\right]\right\} d r
$$

Let us divide the $r$ radius (the cooled part) into $\Delta r$ constants. $\sum \Delta r=r 2-r 1$, where $r 2=150 \mathrm{~mm}$ is the initial radius of the part of the disc cooled with oil and $r l=120$ $\mathrm{mm}$ is the inner radius of the disc. At writing the differential equation, thickness $v=$ constant.

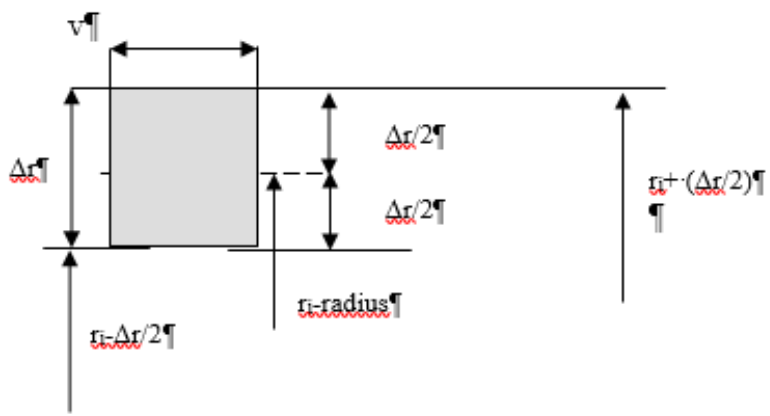

Figure 4. Writing of the differential equations

The differential equation taken in the $r_{i}$ place

$$
\begin{aligned}
& \frac{d A}{d r} \mid r_{i} \cong \frac{A_{\left(r_{i}+\frac{\Delta r}{2}\right)}-A_{\left(r_{i}-\frac{\Delta r}{2}\right)}}{\Delta r} \\
& \frac{d T}{d r} \mid r_{i} \cong \frac{T_{\left(r_{i}+\frac{\Delta r_{i}}{2}\right)}-T_{\left(r_{i}-\frac{\Delta r_{i}}{2}\right)}}{\Delta r}
\end{aligned}
$$

The $\frac{d A}{d r} \mid r_{i}$ value known from the distribution of the disc.

Transformation of the secondary differential: 


$$
\frac{d^{2} T}{d r^{2}} \approx \frac{1}{\Delta r}\left[\frac{T_{\left(r_{i}+\Delta r\right)}-T_{\left(r_{i}\right)}}{\Delta r}-\frac{\left.T_{\left(r_{i}\right)}-T_{\left(r_{i}-\Delta r\right.}\right)}{\Delta r}\right]=\frac{1}{\Delta r^{2}}\left[T_{\left(r_{i}+\Delta r\right)}-2 T_{\left(r_{i}\right)}+T_{\left(r_{i}-\Delta r\right)}\right]
$$

Here, the difference of the two differential values was taken, since it is secondary. Since $\Delta r$ occurs twice, $\Delta r i / 2$ shall be replaced by $\Delta r i-t$. As per equation (13), the transferred secondary derived term still needs to be multiplied by the A(r) value.

$$
A_{(r)} \frac{d^{2} T}{d r^{2}}=A_{(r i)} \frac{1}{\Delta r^{2}}\left[T_{\left(r_{i}+\Delta r\right)}-2 T_{\left(r_{i}\right)}+T_{\left(r_{i}-\Delta r\right)}\right]
$$

The term $\left[T_{\left(r_{i} \mid \Delta r\right)}-2 T_{\left(r_{i}\right)}+T_{\left(r_{i} \Delta r\right)}\right\rfloor$ is little; its value is practically zero.

The complete differential equation is formed as follows:

$$
\lambda\left\{\begin{array}{l}
{\left[\frac{A_{\left(r_{i}+\frac{\Delta r}{2}\right)}-A_{\left(r_{i}-\frac{\Delta r}{2}\right)}}{\Delta r}\right]\left[T_{\left(r_{i}+\frac{\Delta r}{2}\right)}-T_{\left(r_{i}-\frac{\Delta r}{2}\right)}\right]+} \\
+A_{\left(r_{i}\right)} \frac{1}{\Delta r^{2}}\left[T_{\left(r_{i}+\Delta r\right)}-2 T_{\left(r_{i}\right)}+T_{\left(r_{i}-\Delta r\right)}\right]
\end{array}\right\}-4 \alpha_{\text {olaj }} \pi r_{i} \Delta r\left(T_{\text {disc }}-T_{\text {oil }}\right)=0
$$

The $\Delta \mathrm{T}(\mathrm{r})$ value can be expressed from the differential equation with the following solutions:

- the geometrical values are known,

- $\lambda$; $\alpha$ oil; Toil; values are known,

- the values of the first term [ ] can be explicitly calculated,

- the second term [ ] this the $\Delta \mathrm{ri}$-size disc element, the $\Delta \mathrm{Ti}$ is the temperature change,

- the value of the third term is with a fair estimation is zero.

All elements are known in the fourth element, with the exception of Ti. The Ti is the average temperature of the ith disc element.

$$
T_{i}=T_{\left(i+\frac{\Delta r}{2}\right)}-\Delta T_{(i)}
$$

Therefore, the only remaining unknown element of the differential equation is $\Delta \mathrm{Ti}$. With that, the next disc element becomes calculable up to the inner disc diameter. Therefore, the disc temperature change can be defined, which, with a fair estimation 
is the same as the temperature in the boundary layer of the cooling oil. This temperature defines the life cycle of the oil.

\section{The heat distribution of the separator disc}

The following data were used at solving the equation:

- the largest radius of the separator disc is $r_{e t}=224.8 \mathrm{~mm}$,

- the smallest radius of the separator disc is $r_{e t 2}=148.5 \mathrm{~mm}$,

- the temperature of the cooling oil $T_{\text {oil }}=80^{\circ} \mathrm{C}$,

- the temperature of the largest radius of the separator disc to be cooled $T_{e t}=186.7^{\circ} \mathrm{C}$,

- thickness of the subject disc $v_{e t}=12 \mathrm{~mm}$,

- the heat transfer factor of the cooling oil $\alpha_{o i l}=1300 \mathrm{~W} / \mathrm{m}^{2} \mathrm{~K}$ [11],

- the heat conduction factor relevant to the disc $\lambda_{e t}=50 \mathrm{~W} / \mathrm{mK}$ [11],

- the calculation frequency taken at defining the radial temperature change of the disc: $\Delta R=0.1 \mathrm{~mm}$.

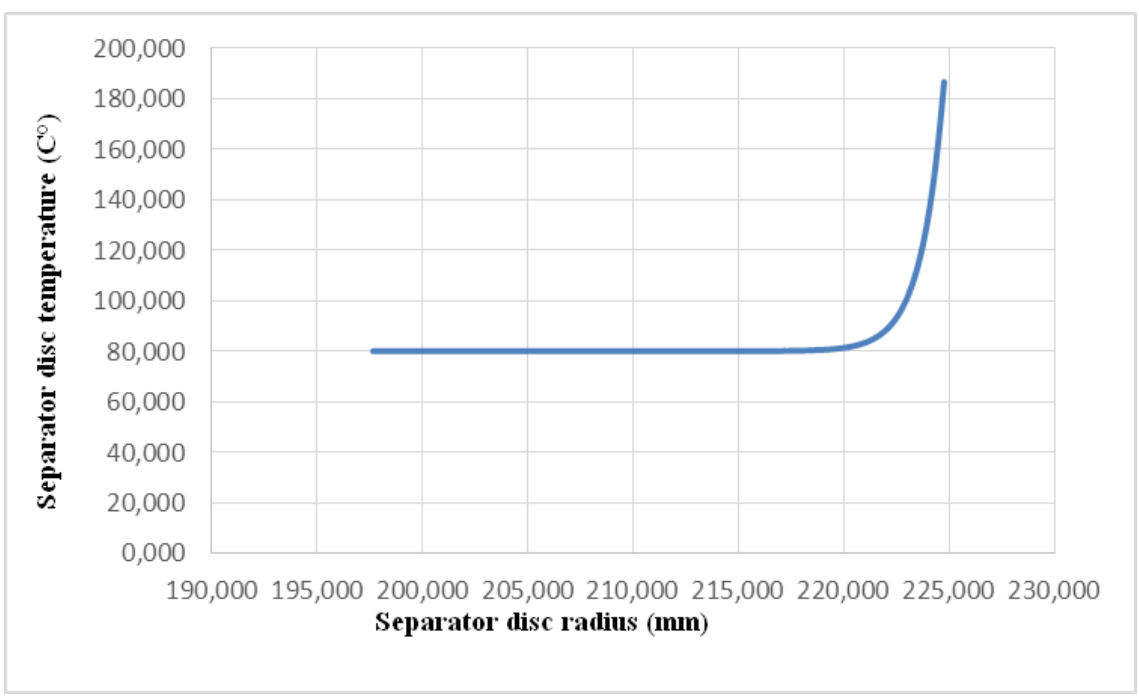

Figure 5. Radial heat change of the separator disc

The temperature of the separator disc, according to the boundary condition decreases towards the centre of the disc. Since only an amount of heat enters the system that is enough for maintaining the temperature on the largest radius of the disc, the temperature becomes equalized after a relatively few steps of calculation. 
On the radius of $218.5 \mathrm{~mm}$, the temperature will, with a fair estimation, be approximately the same as that of the cooling oil.

Similarly to the separator disc, the lower part of the brake disc is also set in cooling oil along the braking process, at which the upper part of the brake disc, similarly to the separator disc receives significant heat load. The heat exchange differential equation can also be written on this part of the disc being cooled in oil.

\section{The heat distribution of the brake disc}

The following data were used at solving the equation:

- largest radius of the brake disc $r_{f t}=224.4 \mathrm{~mm}$,

- smallest radius of the brake disc $r_{f t 2}=150 \mathrm{~mm}$,

- temperature of the cooling oil $T_{\text {oil }}=80^{\circ} \mathrm{C}$,

- temperature of the largest radius of the brake disc to be cooled $T_{f i}=172.2^{\circ} \mathrm{C}$,

- thickness of the subject disc $v_{f i}=5 \mathrm{~mm}$,

- heat exchange factor of the subject disc $\alpha_{o i l}=1300 \mathrm{~W} / \mathrm{m}^{2} \mathrm{~K}$ [11],

- heat exchange factor relevant to the subject disc $\lambda_{f t}=43 \mathrm{~W} / \mathrm{mK}$ [11],

- at defining the radial temperature change of the disc, the calculation frequency taken is $\Delta R=0.1 \mathrm{~mm}$.

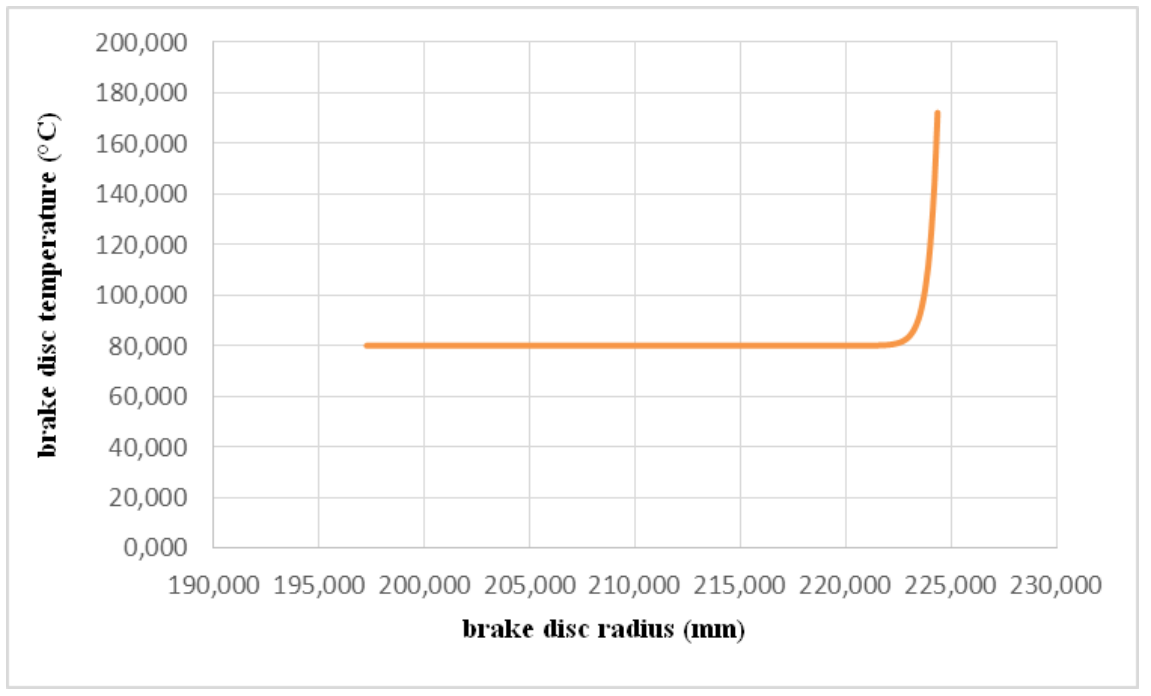

Figure 6. Radial heat change of the brake disc 
As shown on the Figure 6, the result curve is similar to the result curve of the separator disc, it is because during writing the problem, same boundary conditions were used. Difference between the result curves can not only be seen because of the initial temperature but also due to the disc thickness and the significant difference of the heat changing factor as well. The disc already drops its temperature to that of the cooling oil already on the radius of $222 \mathrm{~mm}$.

As can be seen from the results, the temperature of the disc drops in balance with the decrease of the radius concerned. Its maximum temperature is at the external radius (where the calculation begins), where this is the boundary condition.

The oil does not start being spoiled even at the maximum temperature of the disc material. The oil does not get damaged at the smaller radius of the disc since the temperature of the oil adhering to the boundary layer is smaller all around than the damaging temperature of the oil.

\section{Summary}

Following the short description of the brake unit, the study defines boundary conditions and writes a differential equation, with the help of which the temperature distribution of the part of the disc set in oil can be defined. After transferring the differential equation to derivation, the equation becalms possible to be solved even numerically. The author presents the radial heat distribution of the separator disc.

\section{Acknowledgement}

Special thank to Dr. Zobory István prof. emeritus who helped me in transforming the differential equation into differential equation, and to Takács Krisztián for the simulation results.

\section{References}

[1] W. I. Lokaj, M. N. Bodunow, W. I. Dewjatow, Kühlung bestimmte Elementen GTU, hergestellt AN. Sowjetunion/UDSSR, OTN, Energie und Transport, (3) (1968)

[2] M. Menyhártné Baracskai, Power Engineering of Brake System of a Heavy Duty Agricultural Motor Vehicle, Acta Mechanica Slovaca, 18 (2) (2014) pp. 28-35. 
[3] J. S. Jiang, Analysis on Wet Multi-Disc Brake Based on ABAQUS, Advanced Materials Research, 421 (2012) pp. 427-430.

DOI: $10.4028 / w w w . s c i e n t i f i c . n e t / A M R .421 .427$

[4] C. Spulber, S. Voloaca, Comparison between some Simulation Methods Regarding the Thermal Stress on Disc Brake, Applied Mechanics and Materials, 325-326 (2013) pp. 135-141.

DOI: 10.4028/www.scientific.net/AMM.325-326.135

[5] J. Zhang, C. G. Xia, Research of the Transient Temperature Field and Friction Properties on Disc Brakes, Advanced Materials Research, 756-759 (2013) pp. 4331-4335.

DOI: $10.2991 /$ iccia.2012.49

[6] M. Bogdevicius, J. Janutėnienè, O. Vladimirov, Simulation of Hydrodynamics Processes of Hydraulic Braking System of Vehicle, Solid State Phenomena, 147-149 (2009) pp. 296-301.

DOI: $10.4028 / w w w . s c i e n t i f i c . n e t / S S P .147-149.296$

[7] J. B. Wang, M. Han, D. Y. Yu, Appropriate Mass Flow Research of Lubricant for Different Oil Groove Type of Wet Multi-Disc, Advanced Materials Research, 490-495 (2012) pp. 2366-2370.

DOI: $10.4028 /$ www.scientific.net/AMR.490-495.2366

[8] X. J. Zheng, T. H. Luo, C. Jia, Dynamic Response Modeling of Fluid-Solid Coupling for Wet Brake Disc, Applied Mechanics and Materials, 475-476 (2014) pp. 1397-1401.

DOI: 10.4028/www.scientific.net/AMM.475-476.1397

[9] Z. Hu, M. Han, Z. C. Song, K. Y. Ning, Numerical Investigation on Thermo Mechanical Behavior in Wet Multidisc Friction Pairs System, Applied Mechanics and Materials, 697 (2015) pp. 177-180.

DOI: 10.4028/www.scientific.net/AMM.697.177

[10] E. Pásztor, Untersuchung der Wirkung der Kühlung von Gasturbinen Scheiben, Periodica Politechnica. Ser. Transp. Eng., 34 (1-2) (2006) pp.8592.

[11] K. Ražnjević, Thermal Technical Tables, Müszaki Könyvkiadó, Budapest, 1964, in Hungarian. 
[12] W. Zielenkiewicz, E. Margas, Theory of Calorimetry, Kluwer Academic Publishers, Dordrecht, 2002.

[13] Z. Hu, M. Han, Z. C. Song, K. Y. Ning, Numerical Investigation on Thermo Mechanical Behavior in Wet Multidisc Friction Pairs System, Applied Mechanics and Materials, 657 (2015) pp. 177-180.

DOI: 10.4028/www.scientific.net/AMM.697.177

[14] F. Talati, S. Jalalifar, Analysis of heat conduction in a disk brake system, Heat and mass transfer, 45 (8) (2009) pp. 1047-1059.

DOI: $10.1007 / \mathrm{s} 00231-009-0476-y$

[15] H. Mazidi, S. Jalalifar, J. Chakhoo, Mathematical modeling of heat conduction in a disk brake system during braking, Asian Journal of Applied Sciences, 4 (2) (2011) pp. 119-136.

DOI: 10.3923/ajaps.2011.119.136

[16] O. Huajiang, N. Wayne, Y. Yuan, F. Chen, Numerical analysis of automotive disc brake squeal: A review, International Journal of Vehicle Noise and Vibration, 1 (3-4) (2005) pp. 207-230.

DOI: $10.1504 / I J V N V .2005 .007524$

[17] M. Menyhártné Baracskai, K. Takács, Thermal analysis and optimization of oily disc brakes of a high performance vehicle, Hadmérnök 12 (2) (2017) pp. 299-309, in Hungarian 